$\mathcal{E}_{\text {Iransport Forum }}^{\text {International }}$

\title{
Public Transport Provision in Rural and Sparsely Populated Areas in Norway
}

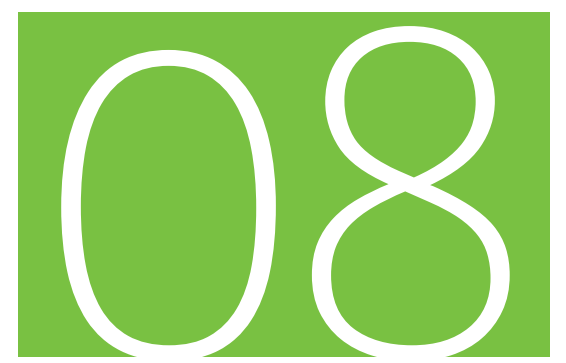

Discussion Paper 2015• 08

Merethe Dotterud Leiren and Kåre Skollerud

Institute of Transport Economics, Oslo, Norway 


\section{Public Transport Provision in Rural and Sparsely Populated Areas in Norway}

Discussion Paper No. 2015-08

Merethe DOTTERUD LEIREN Kåre SKOLLERUD

Institute of Transport Economics, Oslo, Norway

March 2015 


\section{THE INTERNATIONAL TRANSPORT FORUM}

The International Transport Forum at the OECD is an intergovernmental organisation with 54 member countries. It acts as a strategic think-tank, with the objective of helping shape the transport policy agenda on a global level and ensuring that it contributes to economic growth, environmental protection, social inclusion and the preservation of human life and well-being. The International Transport Forum organises an Annual Summit of ministers along with leading representatives from industry, civil society and academia.

The International Transport Forum was created under a Declaration issued by the Council of Ministers of the ECMT (European Conference of Ministers of Transport) at its Ministerial Session in May 2006 under the legal authority of the Protocol of the ECMT, signed in Brussels on 17 October 1953, and legal instruments of the OECD.

The Members of the Forum are: Albania, Armenia, Australia, Austria, Azerbaijan, Belarus, Belgium, Bosnia and Herzegovina, Bulgaria, Canada, Chile, China (People's Republic of), Croatia, Czech Republic, Denmark, Estonia, Finland, France, Former Yugoslav Republic of Macedonia, Georgia, Germany, Greece, Hungary, Iceland, India, Ireland, Italy, Japan, Korea, Latvia, Liechtenstein, Lithuania, Luxembourg, Malta, Mexico, Republic of Moldova, Montenegro, Netherlands, New Zealand, Norway, Poland, Portugal, Romania, Russian Federation, Serbia, Slovak Republic, Slovenia, Spain, Sweden, Switzerland, Turkey, Ukraine, United Kingdom and United States.

The International Transport Forum's Research Centre gathers statistics and conducts co-operative research programmes addressing all modes of transport. Its findings are widely disseminated and support policymaking in member countries as well as contributing to the Annual Summit.

\section{Discussion Papers}

The International Transport Forum's Discussion Paper Series makes economic research, commissioned or carried out at its Research Centre, available to researchers and practitioners. The aim is to contribute to the understanding of the transport sector and to provide inputs to transport policy design.

ITF Discussion Papers should not be reported as representing the official views of the ITF or of its member countries. The opinions expressed and arguments employed are those of the authors.

Discussion Papers describe preliminary results or research in progress by the author(s) and are published to stimulate discussion on a broad range of issues on which the ITF works. Comments on Discussion Papers are welcomed, and may be sent to: International Transport Forum/OECD, 2 rue André-Pascal, 75775 Paris Cedex 16, France.

For further information on the Discussion Papers and other JTRC activities, please email: itf.contact@oecd.org

The Discussion Papers can be downloaded from: www.internationaltransportforum.org/jtrc/DiscussionPapers/jtrcpapers.html

The International Transport Forum's website is at: www.internationaltransportforum.org

This document and any map included herein are without prejudice to the status of or sovereignty over any territory, to the delimitation of international frontiers and boundaries and to the name of any territory, city or area. 


\section{Table of contents}

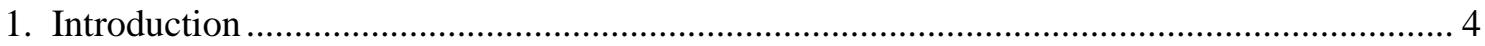

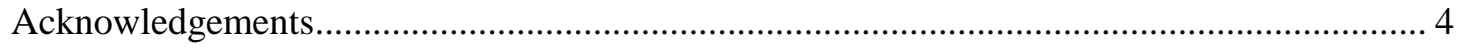

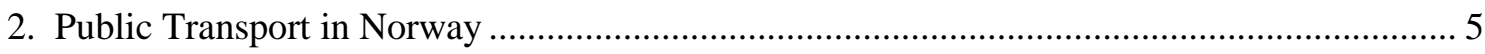

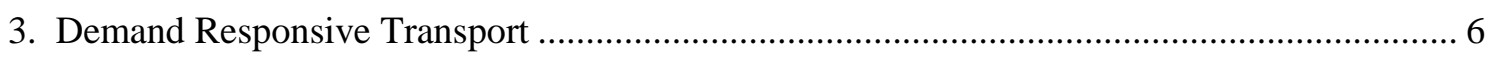

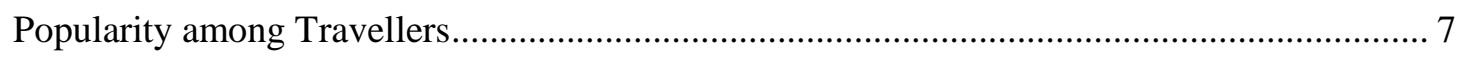

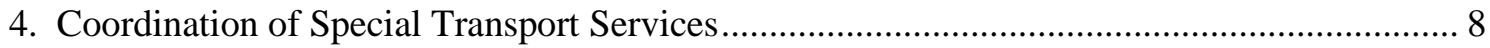

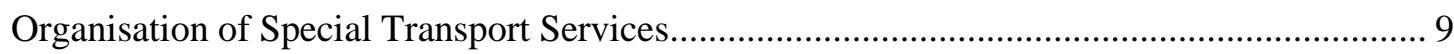

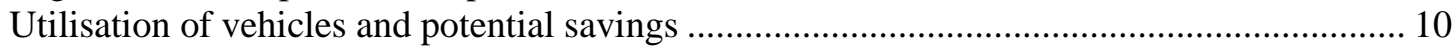

The Market of the Transport Providers................................................................................ 12

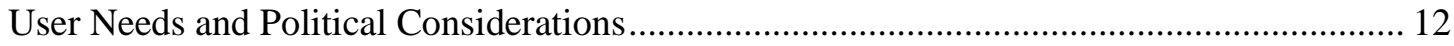

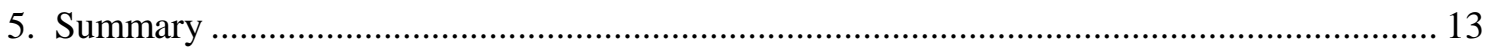

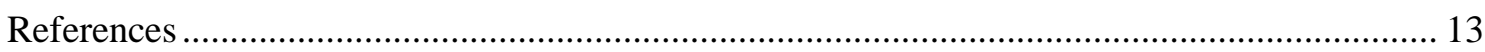




\section{Introduction}

Norway and Finland share several commonalities, being Nordic democracies with a population of 5.1 and 5.5 million and large rural areas. With decreasing population in rural areas, given aging and structural changes in society, both countries face challenges in trying to keep the costs of passenger transport services down while ensuring an adequate standard of service nationwide. Grappling with similar issues, experiences and information about different policies in Norway may provide useful information to the Finnish Government. This contribution therefore provides some insights into public transport provision in rural and depopulated areas in Norway, how the public authorities have attempted to solve efficiency issues while maintaining good quality services and related experiences sparsely populated rural areas. It includes aspects concerning the market of transport providers, user needs and political barriers of reform.

In both Finland and Norway there are many different authorities that are responsible for the administration, procurement and planning of various passenger transport services. In both countries there are concerns with increasing costs and certain public authorities are interested in using coordination among different organisations in order to exploit potential savings, while retaining an adequate level of public services, also in rural areas. This working document includes references to Denmark, as certain Danish municipalities have coordinated their special transport services to a larger extent than in for example Norway.

The roadmap is as follows. First, we give an overall introduction to public transport in Norway. Second, we introduce the concept of demand responsive transport, giving different examples and addressing the popularity among travellers. Third, we describe the possibilities and barriers to coordination of special public transport services, including how different services are organised, utilisation of vehicles and potential savings as well as user needs and political considerations.

\section{Acknowledgements}

We would like to thank our contact person in OECD, Jari Kauppila, for information about the situation in Finland and constructive discussions via telephone. We are also grateful to our colleagues, Julie Runde Krogstad and Jørgen Aarhaug, for their contributions in particular in the project Integration of special passenger transportation services in Akershus and Oslo (Leiren et al 2014), where much of the data used in this working paper has been collected. We would also like to thank Frode Longva, who has ensured the quality of this work. 


\section{Public Transport in Norway}

Public passenger transport services are important for the welfare of citizens and the environment. However, given large areas with dispersed population in Norway, ordinary local public transport services are lacking or even non-existing in many rural areas. In such areas the only existing public transport service is school transport, other special transport services and taxi services.

The regional level (i.e. counties) is responsible for the provision of local public transport in Norway, primarily bus, but also boat, tram and metro services. Taxis are private. The national government is responsible for the provision of railway services. Special transport services are in the hands of different political authorities (see part 3). There is also a commercial bus market for express coaches and flight buses. In certain rural areas such express coaches play an important role as a local transport service. Sometimes counties therefore subsidise such express coach companies to provide local fares for local travels (Leiren et al 2007; Aarhaug, Christiansen \& Fearnley 2011).

Norway is a member of the European Economic Area and is therefore obliged to implement European Union law. The Norwegian government has transposed the EU procurement regulations and the Public Service Obligations for Public Passenger Transport Regulation into national law. Today a large majority of the regional authorities use competitive tendering when awarding contracts for local public transport services. There has been a shift from net cost contracts to gross cost contracts, meaning that the responsibilities for planning of services and income have been moved from the operating companies to the public authorities (Longva \& Osland 2010). At the same time, there has been an increase in public transport agencies, which carry out planning and procuring on behalf of the regional public transport authorities. 10 out of 19 regional authorities have established such quasiautonomous agencies (Leiren forthcoming).

The counties receive government transfers that they use to finance local public transport services. The amount of subsidies to finance public transport varies from county to county. In the capital urban area, which is the biggest urban area in Norway, public funding was about 44 per cent, while fares represented about 56 per cent of the public transport company's revenues in 2012 (Ruter 2012). In contrast to this, the county of Hedmark, a county characterised by rural areas and where school transport imposes the largest costs, public funding came to about 90 per cent of the public transport companies' revenues in 2013, while the fares amounted to about 10 per cent (Hedmark Trafikk 2013).

Public transport in rural areas is costly because of long distances and few passengers. In contrast to urban areas, where the aim is to create a shift from private car to public transport in order to reduce congestion, environmental pollution and climate gas emissions, public transport services in rural areas is primarily a service to people who do not have access to private car transport.

In order to strengthen the public transport services in rural areas, the national government introduced the grant 'Public transport in rural areas' in 2007. The aim is to contribute with solutions that may improve public transport services in rural areas through more effective coordination of resources and means. Counties implement projects with a 50 percent deductible, so that state support comes as an addition to and not a substitute for funds from the regional authorities. The aim is to implement measures at selected locations and routes to achieve a substantial strengthening of public 
transport services to passengers in rural areas. The measures should be transferable to other areas. The Ministry of Transport and Communications put great emphasis on dissemination of experience and knowledge. A part of the allocated funds goes to mediation seminars and consultancy.

To make public transport services in rural areas more efficient and improved, possibilities to coordinate special transport services have been discussed (Ministry of Health and Care Services 2008). However, the different responsibilities and administrative boundaries create barriers for such coordination. Another challenge is to maintain taxi services in rural areas. Given unfavourable working hours and low demand of commercial taxi services, services are decreasing in certain rural areas (Longva et al 2010). This may create certain issues when designing procurements, if the aim is to ensure a certain level of taxi services in such areas.

\section{Demand Responsive Transport}

In 2007 the Norwegian government launched a political package containing financial means for developing new systems for public transport in rural districts in Norway. As a response to this, different models of demand-responsive services were developed for some sparsely populated areas in Norway. The services are different when it comes to target groups, frequency and flexibility, but all of them require that the travellers make a request for the service by phone at minimum two hours in advance.

One example of such demand-responsive service is situated in the south-eastern part of Norway (Østfold). In addition to the regular express bus from the municipality centre to some major cities more than $25 \mathrm{~km}$ away, the inhabitants of the more sparsely populated areas have access to a local demand-responsive service. Initially the services were restricted to people of old age and co-travellers exclusively, but after a certain time the transport authorities opened the services for all users.

The service offers two different routes: One serves the northern part of the area three days a week, while the other serves the southern part on the two other days. Even if the service has specified routes, it is possible for the passengers to be picked up at home up to two kilometres away from the specified route.

There are two departures on each of the service days. The services go in a circle and start and end in the centre of the municipality. The first departure is at about 10 o'clock, i.e. after the school transport is finished in the morning. The second service runs about 3 hours later. This schedule makes it possible to carry out errands in the municipality centre. If nobody demands the service at least two hours in advance of the scheduled departure, there will be no trip. Depending on the number of passengers and their special needs (for example, due to wheelchair) the lines will be serviced by minibuses or regular taxis, owned and administrated by the local taxi central. The service was meant to replace the traditional support for transport for people with special needs (i.e. a yearly amount from the county), subsidising the use of taxi.

Another model for demand-responsive services was developed for a sparsely populated and geographically large municipality in the eastern part of Norway (Hedmark). The public authorities introduced it as a new public transport concept with departures from the municipality centre every hour, if requested at least two hours in advance. The service has fixed 'us' stops and is supposed to pick up or deliver passengers only at these stops. However, from time to time informal solutions are 
made. Maps illustrate the bus stops, but there is no route schedule. The passengers have to be at the bus stop at the time that planners tell them that the service will leave. The planners work in a planning centre that is common for all the municipalities in a greater area.

Regular taxis service the lines. As the stops are fixed, the service is not intended to replace services for people with special needs. The structure of the time schedule is based on the time of departure from and arrivals to the municipality centre: Every route starts from and arrives at the municipality centre half past every hour. The operating time is between seven o'clock in the morning and ten o'clock in the evening on workdays and between nine and 19 o'clock on weekends. From the centre, it is possible to change to railway and express bus services for trips that cross the border of the municipality. The fares are regular and equal to ordinary public transport tickets.

Initially the public transport authorities developed the two mentioned models partly as a response to the opportunity of getting extraordinary funding from the national government as part of the 'Public transport in rural areas' programme. These grants are no longer given and in the aftermath, the two models have taken different paths: While the first concept has been developed further and implemented also in other areas in the county, the future of the second concept is more uncertain. The public procurement agency considers the service as being too expensive. Therefore the company hesitates in continuing the level of services without achieving alternative sources of financing. Currently the county is collecting more information about the number of users and costs and is considering new innovative models as to how to organise public transport services in rural areas.

\section{Popularity among Travellers}

Evidence from areas where the public transport authorities have removed ordinary bus services and replaced them by demand responsive transport services, shows that such new demand responsive transport solutions are popular among the users. Studies of such a pilot, the service "Half past" in the municipality of Tolga in the County of Hedmark, provides insights into how users experience such services (Skollerud 2012). Key user groups are young people and people of older age without a driver's license.

An important characteristic of the typical user is that he or she does not own a car or does not have a driving licence. Access to a car is a more important factor for using the service than the general activity level or age. It is interesting that in particular parents greatly value such transport services, as it relieves them from having to drive their children to activities. Citizens who live outside the municipality centre use the transport service to a greater extent, but also citizens in the municipality centre take advantage of the services. The youngest travellers (between 12 and 18 years old) are diligent users of the service, when going to sports or visiting friends and relatives who do not live in the neighbourhood. Sports teams have adapted their schedules to fit with the transport offer. In contrast to the younger users, people of older age use the service "Half past" in the morning, when going to meetings, treatments or shopping. This group also uses the service in the evenings, for example, when going to senior dances and other events. The association for elderly people arrange walks in the woods by making use of the services.

The first model described in "Popularity among Travellers" has been studied with regard to the use by elderly people. Major findings were that those who had travelled with this new model for public transport were satisfied with the services offered, especially the possibility to be transported all the way from and to their own front door. The impression from the qualitative study was that the purpose for travelling was to a high degree restricted to special errands in the municipality centre, like visiting the bank, doctors or public offices. If possible, shopping food and other things were mostly organised in other ways due to special needs like assistance in the shops and help with the carrying the goods from the grocery to the vehicle. 
In contrast to this "special errands" situation found in the first model, the impression from the study of the "Half Past" (the second) model was that here the public transport services were an integrated part in the organisation of family life, at least when it comes to families with children. One expression for this is the enthusiastic support to the model given from parents interviewed in the study, even if they did not this services themselves. In general, people of older age living in rural areas are concerned with how to be able to maintain their level of activity when they no longer can drive a car (Hjorthol et al 2009). A study by Hjorthol et al (2009) suggests that there are particularly two services that they would like to have: a 'trade route' going to the city centre in the morning and an 'evening' route, which makes it possible to attend meetings and evening events (Hjorthol et al 2009: 54).

Moreover, a survey focusing on transport solutions for people of older age in rural areas suggest that the amount of subsidies that the people of older age get as part of the transport service for people with disabilities, is small compared to their actual transport needs (Hjorthol et al 2009). Almost every respondent answered that he or she supplements such public services with regular taxi services and other private transportation (for example, as provided by family or friends).

\section{Coordination of Special Transport Services}

In addition to the mentioned 'Public transport in rural areas' scheme, there are suggestions of increased coordination of special transport services. The idea is, firstly, to coordinate different types of transport services that are in the hands of different public authorities. This may contribute to a more efficient use of the vehicle fleet as the same vehicle can be used for different types of transport throughout the day. It may also increase the pool of passengers that may be able to travel together in the same vehicle at the same time, thereby contributing to increased efficiency in terms of less numbers of travels.

Secondly, the concept is about opening up special transport services, which today are restricted to citizens with special rights (i.e. 'closed' transport services), to citizens without such travel rights. The aim is to improve the transport services for citizens in rural areas, where the ordinary public transport services are poor or non-existing. Experiences from demand responsive transport services such as in Hedmark shows that such open services are popular among both old and young users, who even reschedule their recreational activities to fit with the routes of such demand responsive transport services (see part 2).

However, open solutions may also provide challenges and for some users, in particular existing users who are used to individual transport solutions, constitute worsened quality of their transport services as compared to the services that they currently enjoy.

Moreover, there is hesitation among certain responsible public authorities. Issues include different management systems and concerns about the rights of certain user groups. Within certain transport areas there are also considerable coordination work going on, which means that the benefits of further coordination may be smaller than for example has been the case in Denmark, where municipalities have achieved considerable savings by cooperating about services using an inter-municipal public transport company for coordination (see "Utilisation of vehicles and potential savings"). For example, hospitals aim to coordinate patient travels with ambulance driving and some municipalities combine the day centre transport with caretaker services. There may also be political provisions that aim to ensure free user choice (i.e. the users can choose the transport company they prefer themselves). This 
may complicate coordination, as in procurement processes the public authorities ensures the winner of the competitive tenders a certain transport volume. If users freely choose between transport operators, there is uncertainty about whether the public authorities can ensure the winning operator the transport volume as agreed upon in contracts between them. Some actors also consider each other as competitors, which is not a convenient starting point for coordination.

\section{Organisation of Special Transport Services}

One objective of coordinating publicly funded passenger transport services is to take advantage of economies of scale. Today, the responsibility for ordinary public transport and the various special transport services are in the hands of several different authorities and organisations. In addition to the ordinary public transport services (see part 1), special transport services such as patient transport, work and educational transport, transport for people with disabilities, school transport and day care centre transport are national, regional or local responsibilities and traditionally associated with the sectors to which they belong (e.g. education and health and not the transportation sector). The responsibilities are fragmented and located at different political levels (see Figure 1). They have various funding sources, sector-specific considerations, passenger rights and legislative rules.

Figure 1. Responsibilities of special transport services

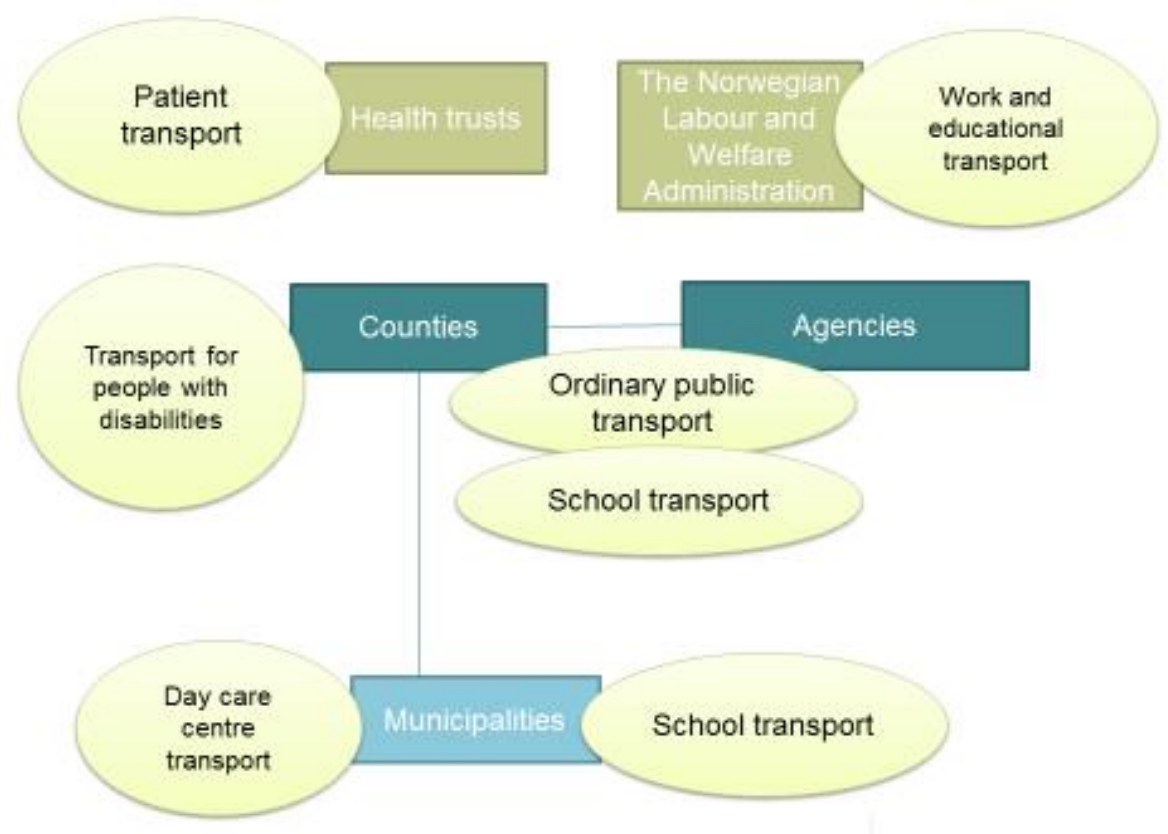

Source: Leiren et al., 2014.

School transport includes transport for pupils - both children and adults - to elementary and high school. It includes ordinary public transport, school routes (fixed routes which are open to all, but that is not running during the school holidays) and special transport solutions for students with special needs due to health issues, place of residence or dangerous school roads in terms of traffic safety. The counties are responsible for organising school transport to elementary and high school pupils, including services for school way distances of more than two or four kilometres (distance depends on the age of the pupils). The regional authorities manage the ordinary school routes in the municipalities. Municipalities have the financial responsibility for the school transportation when the roads are particularly dangerous or difficult, and the distance between home and school is less than two to four kilometres. 
In addition, there are different types of transport services related to school activities such as transport of students to swimming lessons or excursions. The municipalities (or schools) organise such services themselves. While some municipalities purchase such services from operators, other municipalities own their own buses for such transport.

Working and educational transport is a national scheme that ensures people with disabilities the ability to get to and from work or higher education, when lack of transport possibilities otherwise would prevent them from being able to take a job or training. The scheme covers people who are in need of support beyond the basic allowance for transportation for people with disabilities. People with lasting mobility difficulties can get a taxi to and from work or education at the price of a bus ticket in the area where they live. The authorities introduced this as an experiment in 2001. In 2013 it became a nationwide permanent scheme. With the new nationwide scheme everyone, who has been granted work and educational transport, get a travel card and can freely choose between taxi operators.

Social welfare centre transport is a service for people who live at home, but that have special needs and therefore have the right to visit day care centres. Such centres may offer services such as physiotherapist, hairdresser, dinner or other activities. Transportation to and from such centres are in the hands of the municipalities. While some municipalities have their own small buses that they use for such transport, others have outsourced such services for example to a local taxi company or they have established their own municipal transport company.

Patient transport includes travels to and from the consultation and treatment at hospitals or primary health care. Patient transport is a national responsibility, which the regional health authorities or health trusts implement. The delivery of patient transport sometimes includes a requisition, sometimes not. When a passenger travels without a requisition, the passenger pays for the journey and then applies to get a refund. The health trust covers the cheapest travel alternative. If the traveller does not have the opportunity to make use of scheduled public transport (because it does not exist or it is not possible due to health reasons), the passenger can get a requisition from the patient travel office, which organises transport for example a seat at a health bus that collects passengers.

Transport for people with disabilities is a taxi-based service that aims to contribute to increased mobility and participation in society for people with disabilities in their leisure time. It is a regional responsibility. In most counties, the users receive a subsidy in the form of an electronic card. They use this card as a kind of 'credit card'.

\section{Utilisation of vehicles and potential savings}

Estimates by Kjørstad and Smith (2012) and lessons learnt from the coordination of different public paid transport services in Denmark, suggest that there may be potential savings and economies of scale through coordination of special transport services (Deloitte 2013). In this part, we discuss whether coordination can contribute to lower the cost per journey.

There are three important aspects related to possible savings through coordination of special transport services (see Leiren et al 2014):

- Pooling of passengers

- Utilisation of the vehicle fleet

- Common planning and purchasing

First, coordination contributes to the possibility of viewing more travels together, thereby making it easier to find people who can travel together on the same trip. However, it could imply a 'stiffer' service, i.e. passengers who are used to a transport service that is adapted to them need to adapt to 
transport routes. In cases of door-to-door transport, it also implies increased journey time, having to pick up and wait for other passengers.

Second, coordination may contribute to a higher utilisation of the vehicle fleet. In contrast to the first point, which is about getting more passengers to drive together, higher utilisation of vehicles is also about using the vehicles during a greater part of the day, thereby contributing with cost savings. Travel patterns show that there is activity in the various sub-markets at different times of the day. In the morning and afternoon, there is a lot of school and work travels. Between the rush hours, there is extensive patient transport activity and municipal transport services. In the evening, there is more leisure transport for people with disabilities. In other words, a vehicle can be used for school transportation during rush hours, patient transport during the day and leisure trips for people with disabilities in the evening. This is largely how taxi companies operate. However, different public authorities have contracts with different transport companies, which limits the ability to coordinate across sub-sectors.

Another observation is that the vehicles, which for example the municipalities own themselves, have a low utility rate. In comparison to a taxi, a municipal vehicle is used only $1 / 4$ of the usage of a taxi. It means that there is a lot of free capacity in the municipal fleet. Theoretically, this means that each 'municipal' mile is expensive, given the investment cost of a vehicle that is not much in use. However, the municipality itself may not consider such transport as expensive. When the investment of purchasing a vehicle has already been made (or the municipality has inherited or been given a vehicle as a gift) and labour costs are already covered (for example, if the driver is hired for other work tasks than driving such as caretaking services, but also drives passengers during working hours), such costs are not visible in the budgets. As a result, the municipal-run service is perceived as less expensive than purchased services, where such other costs are included in the payment for each trip.

Third, there may be economies of scale related to common planning and purchasing. If public tenders are designed in such a way that they become more attractive to transport operators, more transport operators could be willing to compete for the services, thereby increasing competition and lowering the price that the public authorities have to pay. Coordination provides the opportunity to look at different transport needs together, and thus lead to different calls for tenders than under the current fragmented distribution of responsibility. However, the effect of such tenders is dependent on the market of transport providers.

Deloitte (2013), in a study of Denmark, argue that there are substantial economies of scale. Deloitte is of the opinion that the Danish municipalities can achieve lower contract prices by coordinating tenders across institutions and administrative boundaries, because they can achieve a greater volume in the bids, making it attractive for more operators to bid. According to Deloitte (2013: 164), the average price difference is about 20 percent higher for special transport in municipalities that provide transport services by themselves without coordinating special transport services internally than for municipalities that use an inter-municipal public transport company to coordinate the services for them. It means that if the municipalities would achieve the same prices as a public transport company, they would save 430 million DKK. By not making use of a common coordination company, but only coordinating the transport services internally in each municipality, the consultant assume that a Danish municipality, on average, can achieve savings of about 5-10 per cent (see Deloitte 2012). In Norway special transport services such as school transport, which make up the largest transport volumes, is already coordinated internally in several areas. It means that the potential savings in Norway is probably smaller than in Denmark.

To sum up, coordination of transport services provides for efficiency gains: the opportunities for driving passengers together is greater, when the pool of passengers is greater. The utilisation of vehicles improves when the same fleet can be used in different sub-markets at different times of the 
day. For example, patient transport and day centre transport occur at times when there is available capacity (i.e. not in rush hours).

\section{The Market of the Transport Providers}

Coordination of services may have implications for the market foundation of the taxi industry, as other actors (for example, mini bus companies that operate under different conditions than taxi companies) may enter the traditional 'taxi markets'. This has already largely happened, particular in the market of patient transport. A consequence is that the income foundation of the taxi industry decreases. This is an issue because the taxi industry has a 24 hour duty to ensure transport, thereby providing emergency preparedness. However, in rural areas the taxi industry to some extent depends on public transport services in order to maintain a sufficient income in areas, where the demand for commercial taxi services is small.

The issue related to the taxi market is complex. In competitive tendering rounds it has occurred that taxi providers have offered a price level, which is higher than the metered rates, such as for 'residue transport'. There are several reasons as to why the public authorities do not always achieve 'quantity discounts' for such transport, for example because the public transport services coincide with transport peaks, where the demand is already high and the car park is already well exploited.

On the one hand, there is an aim to increase the number of transport bidders in competitive rounds. Otherwise, lack of competition may push the prices up and contribute to a cost increase. Therefore mini-bus companies are invited to competitive rounds.

On the other hand, because of the reasons already mentioned there is a concern with lack of taxi services in rural areas. When mini-bus companies win contracts that are crucial for the survival of taxi companies, the transport preparedness related to taxis may disappear.

\section{User Needs and Political Considerations}

A difference between closed and open transport is that closed transport is fitted to individual needs to a greater extent than open transport. Individual needs among vulnerable users limits the potential for driving passengers together and thus the possibilities to open such services to others. While some travellers (e.g. school children and people of older age) seem to enjoy open transport, because of its social aspect (i.e. they like travelling with others), this is not perceived as positive among for example people with disabilities. Some passengers experience that they feel less safe when travelling with others or - in case of work and educational transport - a lack of certainty due to the possibility of delays.

Furthermore, pooling passengers when opening a service for all travellers may result in 'stiffer' services, e.g. the special transport services become more like the ordinary public transport system, where users need to adapt to the transport routes and not vice versa. Resistance to having to adapt to a such offers are expressed among users, who currently benefit from individual transport services and who, because of a disability, feel that they are in an unfortunate situation in the first place, given their disabilities. To introduce political reform that is perceived as a worsening of the offer for existing users is politically difficult, in particular when interest groups are powerful.

To change the principle of transport (e.g. by going from a solution with individual transport to an offer that is more similar to public transport) can be a difficult political decision. If wanted, it is important to draw up clear definitions of quality requirements in cooperation with user groups and drivers - and make the requirements and specifications for quality explicit. Such aspects include for example how long a user has to be prepared to wait for a transport service. A disadvantage of such a 
set of rules is that the specifications may become so rigid that there is a lack of room for flexible solutions in practice.

\section{Summary}

The responsibility for ordinary public transport and the various special transport services are in the hands of several different authorities and organisations in Norway. Grappling with questions about how to keep the costs down, while retaining a good quality service level in rural areas, there is increasing interest in innovative solutions of coordination among public authorities as well as demandresponsive transport services. Evidence suggests that demand responsive transport pilots are popular among the users; however, their popularity makes them expensive. In contrast, integration of special passenger transportation services include benefits such as increased economic savings. A more efficient use of vehicles and more passengers per vehicle contribute to such effects. However, such coordination of transportation services increases the travel time for existing passengers. It is likely to meet resistance from certain powerful user groups. In addition, there are certain organisational barriers, given the different responsibilities and experiences of the various public authorities - at different political levels and sectors - that are responsible for the services today. Another issue is that coordination may decrease the transportation preparedness in sparsely populated areas, where taxi companies may be dependent on public contracts to keep a minimum basis of income.

\section{References}

Deloitte (2013). Trafikselskabernes varetagelse af offentlig befordring. Deloitte Report.

Deloitte (2012). Kortlægning og analyse af befordringsordninger. Deloitte Report.

Hedmark Trafikk (2013). Styrets årsmelding 2013. Hamar: Hedmark Trafikk.

Hjorthol, R., F. Longva, K. H. Skollerud og L. Vågane (2009). Transportløsninger for eldre i distriktene. TØI report 1043/2009. Oslo: Institute of Transport Economics.

Kjørstad, K. og K. Nilsen (2012). Forslag til ny organisering av kollektivtilbudet i distriktene. Rapport 32/2002. Oslo: Urbanet Analyse and NIVI Analyse.

Ministry of Health and Care Services (2008). Pasienttransport og transporttilbud i distriktene. Report by the Ministry. Oslo.

Leiren, M. D. (forthcoming). Re-Integration Failure and Outsourcing Upside: Organisation of Public Transport in Norway. Local Government Studies. 
Leiren, M. D., J. Aarhaug, J. R. Krogstad \& K. Skollerud (2014). Integration of special passenger transportation services in Akershus and Oslo. TØI report 1297/2014. Oslo: Institute of Transport Economics (Norwegian).

Leiren, M. D., H. Samstad, N. Fearnley \& H. Minken (2007). Express Coach Routes - a Complex Market. TØI report 904/2007. Oslo: Institute of Transport Economics (Norwegian).

Longva, F., \& Osland, O. (2010). The effects of tendering in local public transport. Tidsskrift for samfunnsforskning, 3, 387-415.

Longva, F., O. Osland \& M.D. Leiren (2010). Omreguleringer i drosjemarkedet - hvilkealternativer finnes og hva blir konsekvensene? TØI report 1054/2010. Oslo: Institute of Transport Economics (Norwegian).

Ruter (2012): Årsrapport 2012. Oslo: Ruter.

Skollerud, K. (2014). Halv på hel i Tolga. Noen erfaringer og brukerevalueringer. TOI Report 1343/2014. Oslo: Institute of Transport Economics (Norwegian).

Aarhaug, J., P. Christiansen \& N. Fearnley (2011). Status Report about the Express Coach Industry. TØI report 1167/2011. Oslo: Institute of Transport Economics (Norwegian). 
